Document downloaded from:

http://hdl.handle.net/10251/57965

This paper must be cited as:

Igual Ramo, M.; García Martínez, EM.; Camacho Vidal, MM.; Martínez Navarrete, N. (2013). Physicochemical and sensorial properties of grapefruit jams as affected by processing. Food and Bioprocess Technology. 6(1):177-185. doi:10.1007/s11947-011-0696-2.

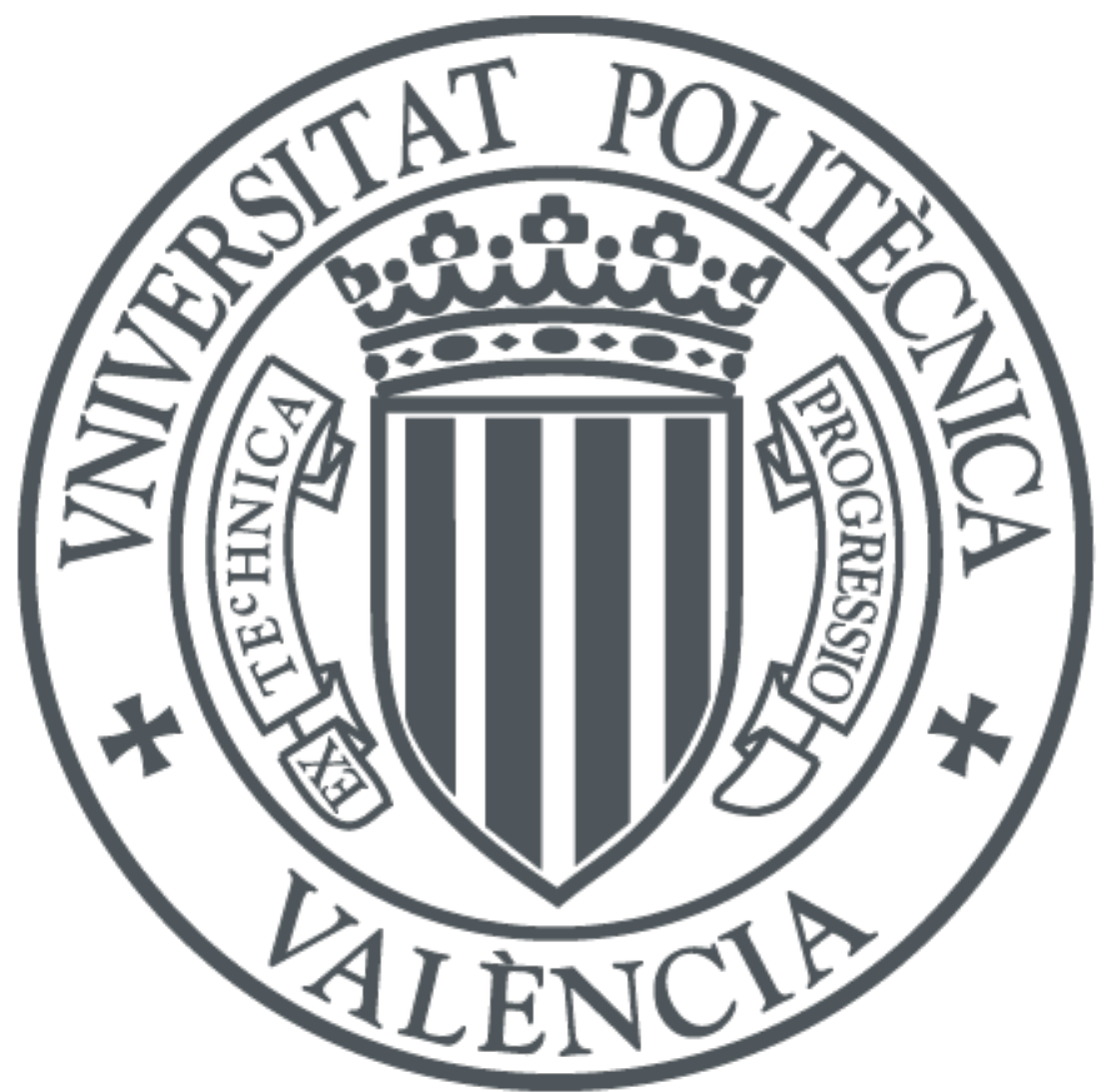

The final publication is available at

http://dx.doi.org/10.1007/s11947-011-0696-2

Copyright Springer Verlag (Germany)

Additional Information 


\title{
PHYSICOCHEMICAL AND SENSORIAL PROPERTIES OF GRAPEFRUIT JAMS AS AFFECTED BY PROCESSING
}

\author{
Marta Igual, Eva García-Martínez, María del Mar Camacho, Nuria Martínez-Navarrete. \\ Food Technology Department, Food Investigation and Innovation Group. Universidad \\ Politécnica de Valencia.
}

Corresponding author: Nuria Martínez-Navarrete. Food Technology Department, Food Investigation and Innovation Group. Universidad Politécnica de Valencia. Camino de Vera s/n, 46022 Valencia, Spain Tel.: +34 96387 9362; fax: +34 9638773 69. E-mail address: nmartin@tal.upv.es

\begin{abstract}
Jam is an effective and tasty way of preserving fruit. Jam processing procedures as well as storage conditions and duration are important factors for jam quality. Traditional jam processing involves the application of severe thermal treatments that imply undesirable changes in the product quality characteristics such as colour, texture, flavour and nutritional and functional value. In this work, osmotic dehydration (OD) and/or microwave energy (MW) were proved as adequate to obtain jam with the typical characteristics of water content, ${ }^{\circ}$ Brix, $\mathrm{pH}$ and water activity of jam obtained by conventional thermal heating. The sensory evaluation carried out to compare the product showed that samples submitted to the more intense heating treatments (conventional or MW) were significantly higher scored in colour saturation, brightness, grapefruit taste and extensibility than OD or OD+MW ones. As deduced from the obtained results, OD treatment prevents from grapefruit colour changes and mild MW heating contributes to increase the consistency and decrease of the extensibility of the obtained jam. In this way, OD+MW jam was the preferred by assessors, mainly due to its higher consistency. Sample obtained by this procedure was stable during storage.
\end{abstract}

Keywords: grapefruit, jam, osmotic dehydration, microwaves, consistency, colour, sensory analysis.

Running Title: physicochemical and sensorial properties of grapefruit jams 


\section{Introduction}

There is an increasing demand by consumers for citrus products as consumption has been recognised as an important factor in reducing the risk of several chronic diseases such as cancer (Poulose et al., 2005; Vanamala et al., 2006), osteoporosis (Deyhim et al., 2006) and cerebrocardiovascular diseases (Sanchez-Moreno et al., 2003; Yu et al., 2005). Grapefruit juices and jams are highly appreciated due to their specific taste, flavour and nutritional value.

Historically, jams and jellies were originated as an early effort to preserve fruit for consumption in the off-season (Baker et al., 2005). In traditional jam manufacture, all the ingredients are mixed in adequate proportions and the mix is concentrated by applying a thermal treatment to reach the required final soluble solids content. Nevertheless, this process also implies an undesirable impact in colour, nutritional value and flavour properties due to the high temperature reached in the cooking process. An alternative for jam formulation is to use dehydrated fruit. In this sense, osmotic dehydration enables us to produce fruit products that have good flavour and nutritional content (Shi et al., 1996; García-Martínez et al., 2002). On the other hand, microwave energy has been proposed as an alternative to traditional heat processing in order to better preserve the natural organoleptic characteristics and essential thermolabile nutrients of fresh fruit (Nikdel et al., 1993; Cañumir et al., 2002; Igual et al., 2010a).

Currently, consumers demand the maximum preservation of the endogenous sensory, nutritional and health-related quality of fruit products. An attractive colour is one of the most important characteristics for the jam processing industry, in addition to a typical fruit flavour and convenient jam consistency. The recipe, processing procedures, storage conditions and stability are important factors for jam quality (Wicklund et al., 2005). During processing or storage the characteristic fruit pigments can suffer degradation reactions that result in browning or loss of typical fruit colour. Colour stability of fruit products may be affected by temperature, $\mathrm{pH}$, oxygen, sugar content, ascorbic acid and metals (Dervisi et al., 2001).

Traditionally, jam glass or plastic jars are stored at room temperature before they are opened. Low temperature is generally not regarded as necessary to prevent degradation, as during processing, in addition to thermal treatment, the jam is added both preservatives and sugar and the $\mathrm{pH}$ of the product is usually low. The shelf life of jam is normally 6-12 months (Wicklund et al., 2005). However, in the case of jams produced without heat 
treatment, refrigeration storage is necessary to avoid the development of fermentation reactions (García-Martínez et al., 2002).

The objective of this study was to evaluate how physicochemical $(\mathrm{pH}$, soluble solids, colour and consistency) and sensorial properties of grapefruit jam are influenced by processing (osmotic dehydration, microwave energy and conventional heating) and storage.

\section{Materials and methods}

\subsection{Raw materials}

2.1.1. Fruit

Grapefruit (Citrus paradise var. Star Ruby) from Murcia in Spain was purchased from a local supermarket. Fruit pieces were peeled and cut perpendicularly along the fruit axis, into $10 \mathrm{~mm}$ thick half slices.

\subsubsection{Sucrose and osmotic solution}

Food grade commercial sucrose was used to prepare conventional and microwave (MW) jams. In the case of jam obtained by osmotic dehydration (OD), an osmotic solution (OS) was prepared by mixing an amount of sucrose with distilled water until it was completely dissolved and forming a $65^{\circ}$ Brix syrup.

\subsubsection{Gelling agent}

Citrus peel pectin (60\% degree of esterification, Fluka Biochemika, Switzerland) was used as a gelling agent.

\subsection{Jam preparation procedures}

\subsubsection{Conventional process}

Conventional jam was obtained by mixing fresh fruit and sugar in a 67:33 ratio. Half slices of peeled grapefruit $(500 \mathrm{~g})$ were precooked at $85^{\circ} \mathrm{C}$ for $10 \mathrm{~min}$. After the addition of sugar $(250 \mathrm{~g})$ and $100 \mathrm{ppm}$ of potassium sorbate (Panreac, Barcelona, Spain), the mixture was cooked for a further $20 \mathrm{~min}$ at $95-100^{\circ} \mathrm{C}$ to reach a $40-60{ }^{\circ}$ Brix product as described in the Spanish quality norm for fruit jam approved by RD 670/1990 (BOE № 130, 1990). The process was carried out in an electrical food processor (Thermomix TM 21, Vorwerk, 
Spain). The jam was placed in sterile glass jars and stored at room temperature for $24 \mathrm{~h}$ until analysis.

\subsubsection{Microwave process (MW)}

A household microwave (Moulinex 5141 AFW2, Spain) was used to produce the MW jam, mixing fresh fruit and sugar in a 67:33 ratio. Half slices of peeled grapefruit $(500 \mathrm{~g})$ were precooked at $900 \mathrm{~W}$ for $5 \mathrm{~min}$. After the addition of sugar $(250 \mathrm{~g})$ and $100 \mathrm{ppm}$ potassium sorbate, the mixture was cooked at $900 \mathrm{~W}$ for a further $10 \mathrm{~min}$ to reach $40-60{ }^{\circ} \mathrm{Brix}$ (BOE № 130, 1990). The jam was placed in glass jars and stored at room temperature for $24 \mathrm{~h}$ until first analysis.

\subsubsection{Osmotic process (OD)}

According to a previous kinetic study (Igual et al., 2010b), half-slices of grapefruit were osmo-dehydrated in the $\mathrm{OS}$ at $40^{\circ} \mathrm{C}$ for $3 \mathrm{~h}$ reaching $\approx 30^{\circ}$ Brix. Osmo-dehydrated samples were ground together with part of the OS to obtain jam with $60 \mathrm{~g}$ fresh fruit/100 $\mathrm{g}$ jam, 100 ppm potassium sorbate, and 1\% of pectin as a gelling agent. Jams were placed in glass jars and stored at room temperature for $24 \mathrm{~h}$ until first analysis.

\subsubsection{Combined osmotic-microwave process (OD+MW)} Jams obtained from osmo-dehydrated grapefruit, as described in Section 2.2.3, were cooked at $900 \mathrm{~W}$ for $5 \mathrm{~min}$. New jams were placed in glass jars and stored at room temperature for $24 \mathrm{~h}$ until first analysis.

\subsection{Storage conditions}

The jams were stored for 3 months at room temperature, except the OD one which was stored at $4{ }^{\circ} \mathrm{C}$, according to previous studies (García-Martínez et al., 2002). Analyses were carried out after $1,7,15,30,45,60,75$ and 90 days of storage.

\subsection{Analysis}

\subsubsection{Physicochemical properties}

Moisture content ( $x_{w}, g$ water/g product), Brix (g soluble solids/100 g liquid phase) and water activity $\left(a_{w}\right)$ were determined for fresh grapefruit and all the formulated jams. The $x_{w}$ was determined by drying the sample to a constant weight at $60{ }^{\circ} \mathrm{C}$ in a vacuum oven 
(AOAC method 934.06, 2000). Brix were measured in previously homogenised samples with a refractometer at $20^{\circ} \mathrm{C}$ (Zeiss, ATAGO model NAR-3T refractometer, Japan). A dew point hygrometer (FA-st Lab, GBX, France) was used to analyze $\mathrm{a}_{\mathrm{w}}$ and $\mathrm{pH}$ was measured with a CRISON pH-meter. Each analysis was carried out in triplicate.

\subsubsection{Colour measurement}

Colour values were obtained from the reflection spectrum (Minolta, CM 3600D, Tokyo, Japan). CIE-L*a*b* uniform colour space was selected to calculate colour coordinates, where $L^{*}$ indicates lightness, $a^{*}$ indicates chromaticity on a green (-) to red $(+)$ axis and $b^{*}$ chromaticity on a blue (-) to yellow (+) axis. Colour coordinates were obtained from a 10응 observer and D65 illuminant. The colour coordinates were then used to calculate the hue angle (Equation 1), chrome (Equation 2) and total colour differences (Equation 3) with respect to the fresh grapefruit sample or conventional jam.

$$
\begin{aligned}
& \mathrm{h}_{\mathrm{ab}}{ }^{*}=\arctan \frac{\mathrm{b}^{*}}{\mathrm{a}^{*}} \\
& \mathrm{C}_{\mathrm{ab}}{ }^{*}=\sqrt{\mathrm{a}^{* 2}+\mathrm{b}^{\star 2}} \\
& \Delta \mathrm{E}=\sqrt{\Delta \mathrm{L}^{* 2}+\Delta \mathrm{a}^{* 2}+\Delta \mathrm{b}^{* 2}}
\end{aligned}
$$

\subsubsection{Consistency}

The flow distance of a controlled sample weight for a constant time was measured using a Bostwick consistometer. This device consists of a level stainless-steel trough divided into two compartments. The first compartment initially containing the sample $(5 \times 5 \times 3.8 \mathrm{~cm})$ is separated from the second by means of a spring-loaded gate. The second compartment is a trough $5 \mathrm{~cm}$ wide, $24 \mathrm{~cm}$ long, and about $2.5 \mathrm{~cm}$ high and has a series of parallel lines drawn across the floor at $0.5 \mathrm{~cm}$ intervals. Once the gate is opened, the distance the sample flows in $30 \mathrm{~s}$ was measured (Bourne, 1982). The parameter used to characterise the consistency of the samples was the distance advanced by the samples in the consistometer related to the weight of the samples $(\mathrm{mm} / \mathrm{g})$.

\subsection{Sensory evaluation}

A panel of 50 tasters carried out a sensory analysis of the jams. The age of the panellists ranged from 20 to 50 years. This analysis consisted of two sessions, the first session was a differentiation test by pairs and the second session was a preference test by pairs (UNE- 
EN ISO 5495). The attributes evaluated at the first session were colour saturation, luminosity, brightness, smell, body or consistency, product coverage in mouth, extensibility and grapefruit flavour. During the test sessions, panellists worked in individual booths. Samples were served at room temperature in transparent plastic glasses coded with random three digit numbers. Panellist tasted approximately the same amount of each sample and mineral water was provided to the assessors to rinse their mouths.

\subsection{Statistical analysis}

Analysis of variance (ANOVA), with a confidence level of $95 \%(p<0.05)$, using Statgraphics Plus 5.1 Software (Statistical Graphics Corporation, USA), was applied to evaluate the differences among treatments. Friedman analysis for the pairwise ranking test was undertaken on the data of each taster to know in which attribute the samples showed significant differences (Meilgaard et al., 1999). The significance of these differences was determined by applying Tukey's HSD (Honestly Significance Difference) as a multiple comparison procedure (Meilgaard et al., 1999). Correspondence analysis (CA) was applied to the sensorial results using SPSS program version 16.0. Correlations between sensory and instrumental data were determined using the Pearson correlation coefficient (r).

\section{Results and discussion}

\subsection{Effect of treatment on the physicochemical properties of the obtained jams}

Table 1 shows the physicochemical parameters of fresh grapefruit and Conventional, OD, $\mathrm{OD}+\mathrm{MW}$ and MW jams. Fresh grapefruit presented the characteristic physicochemical parameters shown in the bibliography for grapefruit (Moraga et al., 2009) and grapefruit juice (Igual et al., 2010). The range of ${ }^{\circ}$ Brix of formulated jams was between 46 and 48.5, with the lowest values for jams obtained by OD and OD+MW. These jams (OD, OD+MW) showed significantly higher $\mathrm{pH}$ values than the other samples. The lowest values of $\mathrm{a}_{\mathrm{w}}$ and $x_{w}$ were found in the conventional jam, $0.922 \pm 0.003$ and $0.526 \pm 0.002$, respectively. The colour coordinates, $\mathrm{h}_{\mathrm{ab}}{ }^{*}$ and $\mathrm{C}_{\mathrm{ab}}{ }^{*}$ of the jams appear in Table 2. The colour differences of jam in relation to the fresh fruit sample and to conventional jam also appear in this table. There were significant $(p<0.05)$ differences between fresh fruit and the jams. The values of the coordinates $L^{*}, a, b^{*}$, hue angle and chrome were greater in the case of fresh fruit. MW jam presented values closer to the raw material than the others and the lowest values of $a^{*}$ 
and $b^{*}$ were those of the OD jams. The hue angle of OD+MW and MW showed no significant $(p>0.05)$ differences. Neither were there significant $(p>0.05)$ differences in the hue of conventional and OD samples. In addition, jams that were subjected to heat treatment by conventional or microwave treatment showed the lowest $L^{*}$ values, as observed by Igual et al., (2010b). The OD samples showed the lowest chrome values. OD jam showed the smallest total colour differences in comparison to fresh grapefruit, while MW and OD+MW showed the smallest colour difference when compared to the conventional samples. Nevertheless, as $\Delta \mathrm{E}$ among jams was $\leq$ than 3 units in all the cases, differences no noticeable to the human eye exist among them (Bodart et al., 2008). The values of flow distance related to the sample weight $(\mathrm{mm} / \mathrm{g})$ appear in Table 2 . The conventional sample was the least consistent (highest distance advanced). Jams obtained by the application of microwaves showed higher $(p<0.05)$ consistency than conventional jam, probably as a consequence of the higher pectin solubilisation occurred with this process (Contreras et al., 2008). OD showed the same consistency as MW. In this case, this consistency was achieved due to added pectin. The thickest $(p<0.05)$ jam was obtained when combined OD+MW was applied.

\subsection{Sensory analysis}

Figure 1 shows the scores sum of each jam for each evaluated attribute. Regarding the Friedman's T test results, colour saturation, brightness, body or consistency, extensibility and grapefruit taste were the attributes that showed statistical significant differences $(\alpha=0.05)$ in the studied samples. Friedman's T value for these attributes were 110.5, 81.2, 51.8, 9.2 and 32.1, respectively, being 7.81 the theoretical T value $(\alpha=0.05)$. The HSD method was used to perform a multiple comparison among the treatments. The calculated Tukey's HSD value according to assay conditions was 25.67. Table 3 shows the differences between the sum of ranks for each pair of samples for the attributes that showed significant differences among samples as deduced from Friedman's T test. OD was the jam with the lowest values of colour saturation followed by OD+MW. The score of this attribute was greatest for MW and conventional jams, with no differences between them. OD and OD+MW were perceived with lower brightness and grapefruit taste than MW and conventional jams. As regard to the textural attributes, only OD and conventional samples presented significant differences in extensibility, the last one being scored as more extensible. MW and conventional jams were scored with lower consistency than MDO and MDO+MW. The added pectin in these samples could justify these results. No 
significant differences were detected among samples in the rest of the attributes evaluated.

As regards to the results of the preference test, score obtained by OD+MW jam was 108 , OD was 79, MW 63 and the conventional one 50. These differences were statistically significant (Friedman's $\mathrm{T}=37.9$ ). As it can be observed in Table 3, the jam OD+MW was the preferred by the assessors among any of the others. It was also significant the preference of OD jam when compared to conventional one.

To relate the jams obtained by the different treatments with the attributes evaluated and the preferences of the assessors, a component analysis was carried out. From this analysis, two dimensions that explain $97.2 \%$ of the variability of results were obtained. The first dimension explained $89.3 \%$ of the variability, while the second explained $7.9 \%$. Table 4 shows that both, the jams and the attributes, were well represented along the first two dimensions, since high values were obtained for the sum of the relative contributions in all cases. Figure 2 shows the projection in the plane of the jams and attributes. According to the distribution of attributes and samples in the plane, there were four groups that characterised the jam as follows: MW was identified with higher colour saturation attribute; conventional jam with grapefruit taste, smell, brightness and extensibility attributes; OD with luminosity and product coverage in mouth; and finally, OD + MW was identified with consistency attribute and was also the preferred jam. Furthermore, it can be observed that body or consistency was closely related to the preference of the judges, since they were very near in representation. This shows that consistency has considerable influence on jam acceptance by assessors.

\subsection{Relationship between instrumental and sensory data}

Pearson analysis was used to establish correlations between colour and textural data obtained by instrumental and sensory methods (Table 5). As expected, the results showed a significant positive correlation between sensory luminosity and parameter $L^{*}$. However, no significant correlation was found between sensory colour saturation and $\mathrm{C}^{*}$ ab. This has been also observed in other study referred to a vanilla dairy dessert (Tárrega \& Costell, 2007) and reflects the difficulties for judges in identify the meaning of colour saturation. With respect to flow distance $(\mathrm{mm} / \mathrm{g})$ of studied jams, the only textural attribute that showed a significant correlation was the product coverage in mouth, the greater the flow distance, the lower the product coverage in mouth. 


\subsection{Evolution of colour and consistency of obtained jams during storage}

Figure 3 shows the colour parameters $\left(L^{*}, a^{*}, b^{*}, C^{*}{ }_{a b}\right.$ and $\left.h^{*}{ }_{a b}\right)$ of jams stored for three months. In general, in all studied jams, $L^{*}$ values were maintained during storage. Moreover, $\mathrm{a}^{*}, \mathrm{~b}^{*}$ and $\mathrm{C}^{*}{ }_{\mathrm{ab}}$ were stable in $\mathrm{OD}$ and $\mathrm{OD}+\mathrm{MW}$ samples, whilst these parameters in MW and Conventional jams decreased until 60 days and then remained stable. When the hue angle results were analysed, OD and OD+MW samples showed no significant changes during storage, while MW and Conventional jams showed a significant increase in the first month, related to a change to a less red more orange colour that remains then stable over time. If the global colour changes $(\Delta \mathrm{E})$ occurred at the end of storage as related to the newly processed jams are calculated, using the conventional equation proposed to this end $\left(\Delta E=\left(\Delta L^{*}+\Delta a^{*}+\Delta b^{*}\right)^{1 / 2}\right)$, the obtained values are 2,3 units for MW, 2 for OD, 1 for OD+MW and 0,5 for MW samples. All this values are lower than 3 units, the limit proposed by Bodart et al., (2008) below which colour difference between samples is not noticeable to the human eye.

The evolution of the flow distance corrected by the sample weight of jams stored for three months is shown in Figure 4. The storage time in the OD jam did not show a significant effect. However, in the other samples, the consistency increased (flow distance decreased) significantly $(\mathrm{p}<0.05)$ from day 75 in OD+MW and Conventional samples and during the first week in MW jam. By the end of the storage period, MW sample was the most consistent (flow distance $0.16 \pm 0.02 \mathrm{~mm} / \mathrm{g}$ ) and the one that showed the greatest increase in the consistency, with an increase in this parameter when compared to sample newly processed of $76 \%$.

\section{Conclusion}

The different processes applied to obtain jams can produce products with similar values of water content, Brix, $\mathrm{pH}$ and water activity. In general, when any of the samples submitted to the more intense heating treatments (conventional or MW) were compared with OD or OD+MW ones, significant sensory differences were observed in colour saturation, brightness, grapefruit taste and extensibility, all of them being higher scored in the former. OD+MW sample was the preferred one, mainly due to its higher consistency and the considerable influence of this attribute on jam acceptance by assessors. Sample obtained by this procedure was stable during storage. From the results obtained in this study, intense thermal treatments in jam processing should be recommended to be avoided, 
although mild heating is recommendable as it contributes to a desired increase in the consistency and decrease of the extensibility of the product.

\section{Acknowledgment}

The authors would like to thank the Ministerio de Educación y Ciencia for the financial support given throughout the Project AGL 2005-05994. The language revision of this paper was funded by the Universidad Politécnica de Valencia, Spain.

\section{References}

AOAC (2000). Official Methods of Analysis of AOAC International, 17th ed. Gaithersburg, MD, USA.

Baker, R-A, Berry, N., Hui, Y-H. \& Barrett, D-M. (2005). Fruit Preserves and Jams. Processing Fruits: Science and Technology, Second Edition. Boca Ratón, CRC Press. pp. 113-125.

Bodart, M., de Peñaranda, R., Deneyer, A. \& Flamant, G. (2008). Photometry and colorimetry characterisation of materials in daylighting evaluation tools. Building and Environment, 43, 2046-2058.

BOE № 130. (1990). Real Decreto 670/1990, de 25 de mayo, por el que se aprueba la norma de calidad para confituras, jaleas y marmalade de frutas, crema de castañas y mermelada de frutas.

Bourne, M. (1982). Food texture and viscosity - concept and measurement. New York: Academic Press.

Cañumir, J-A., Celis, J-E., Brujin, J., \& Vidal, L. (2002). Pasteurisation of apple juice by using microwaves. Lebensmittel-Wissenschaft und Technologie, 35, 389-392.

Contreras, C., Martín-Esparza, M-E., Martínez-Navarrete, N. \& Chiralt, A. (2008). Influence of microwave application on convective drying: Effects on drying kinetics, and optical and mechanical properties of apple and strawberry. Journal of Food Engineering, 88, 55-64. 
Dervisi, P., Lamb, J., \& Zabetakis, I. (2001) High pressure processing in jam manufacture: effects on textural and color properties. Food Chemistry, 73, 85-91.

Deyhim, F., Garica, K., Lopez, E., Gonzalez, J., Ino, S., Garcia, M. \& Patil, B-S. (2006). Citrus juice modulates bone strength in male senescent rat model of osteoporosis. Nutrition, 22 (5), 559-563.

García-Martínez, E., Ruiz-Diaz, G., Martínez-Monzó, J., Camacho, M-M., MartínezNavarrete, N., Chiralt, A. (2002). Jam manufacture with osmodehydrated fruit. Food Research Internacional, 35, 301-306.

Igual, M., García-Martínez, E., Camacho, M-M., Martínez-Navarrete, N. (2010a). Effect of thermal treatment and storage on the stability of organic acids and the functional value of grapefruit juice. Food Chemistry, 118, 291-299.

Igual, M., Contreras, C., Martínez-Navarrete, N. (2010b). Non-conventional techniques to obtain grapefruit jam. Innovative Food Science and Emerging Technologies, 11 (2), 335341.

Meilgaard, M., Civille, G-V. \& Carr, B-T. (1999). Attribute differences test. Pairwise Ranking Test: Friedman Analysis. Sensory Evaluation Techniques. Boca Ratón, CRC Press. pp. 103-106.

Moraga, M-J., Moraga, G., Fito, P.J. \& Martínez-Navarrete, N. (2009). Effect of vacuum impregnation with calcium lactate on the osmotic dehydration kinetics and quality of osmodehydrated grapefruit. Journal of Food Engineering, 90, 372-379.

Nikdel, S., Chen, C., Parish, M., MacKellar, D., \& Friedrich, L. (1993). Pasteurization of citrus juice with microwaves energy in a continuous-flow unit. Journal of Agricultural and Food Chemistry, 41, 2116-2119.

Poulose, S-M., Harris, E-D. \& Patil, B-S. (2005). Citrus limonoids induce apoptosis in human neuroblastoma cells and have radical scavenging activity. Journal of Nutrition, 135, 870-877. 
Sanchez-Moreno, C., Plaza, L., De Ancos, B. \& Cano, M-P. (2003). Quantitative bioactive compounds assessment and their relative contribution to the antioxidant capacity of commercial orange juices. Journal of Science of Food and Agriculture, 83, 430-439.

Shi, X-Q., Chiralt, A., Fito, P., Serra, J., Escoin, C., \& Gasque, L. (1996). Application of osmotic dehydration technology on jam processing. Drying Technology, 14(3\&4), 841857.

Tárrega, A. \& Costell, E. (2007). Colour and consistency of semi-solid dairy desserts: Instrumental and sensory measurements. Journal of Food Engineering, 78, 655-661.

UNE-EN-ISO 5495. (2009). Sensory Analysis. Methodology. Paired comparison test. AENOR.

Vanamala, J., Reddivari, L., Yoo, K-S., Pike, L-M. \& Patil, B-S. (2006). Variation in the content of bioactive flavonoid in different brands of orange and grapefruit juices. Journal of Food Composition and Analysis, 157-166.

Wicklund, T., Rosenfeld, H-J., Martinsen, B-K., Sundførb, M-W., Lea, P., Bruun,T., Blomhoff, R. \& Haffner, K. (2005). Antioxidant capacity and colour of strawberry jam as influenced by cultivar and storage conditions. Lebensmittel-Wissenschaft und Technologie 38, 387-391.

Yu, L-L., Zhou, K-K. \& Parry, J. (2005). Antioxidant properties of cold-pressed black caraway, carrot, cranberry, and hemp seed oils. Food Chemistry, 91, 723-729. 


\section{TABLE CAPTIONS}

Table 1. Mean values (and standard deviation) of -Brix, water activity $\left(a_{w}\right)$, moisture content $\left(\mathrm{X}_{\mathrm{w}}\right)$ and $\mathrm{pH}$ of formulated jams and fresh grapefruit.

Table 2. Mean values (and standard deviation) of colour parameters and flow distance of formulated jams and fresh grapefruit.

Table 3. Differences between the sum of ranks for each pair of samples for statistically significant attributes

Table 4. Contribution of dimension to inertia of attributes and jams.

Table 5. Pearson's correlation coefficients between instrumental and sensory parameters. 


\section{FIGURE CAPTIONS}

Figure 1. Score of the different sensory attributes evaluated in grapefruit jams.

Figure 2. Correspondence analysis. Representation of attributes and samples tested in plain with two dimensions.

Figure 3. Evolution of colour parameters (CIE L*a* $\mathrm{b}^{*}$ coordinates, chrome, $\mathrm{C}^{*}{ }_{\mathrm{ab}}$, and hue angle, $\left.h^{*}{ }_{a b}\right)$ of jams stored for three months.

Figure 4. Evolution of the flow distance of jams stored for three months, measured in Bostwick consistometer and corrected for the sample weight. 


\section{Figure 1}

Click here to download Figure: Figure 1.doc

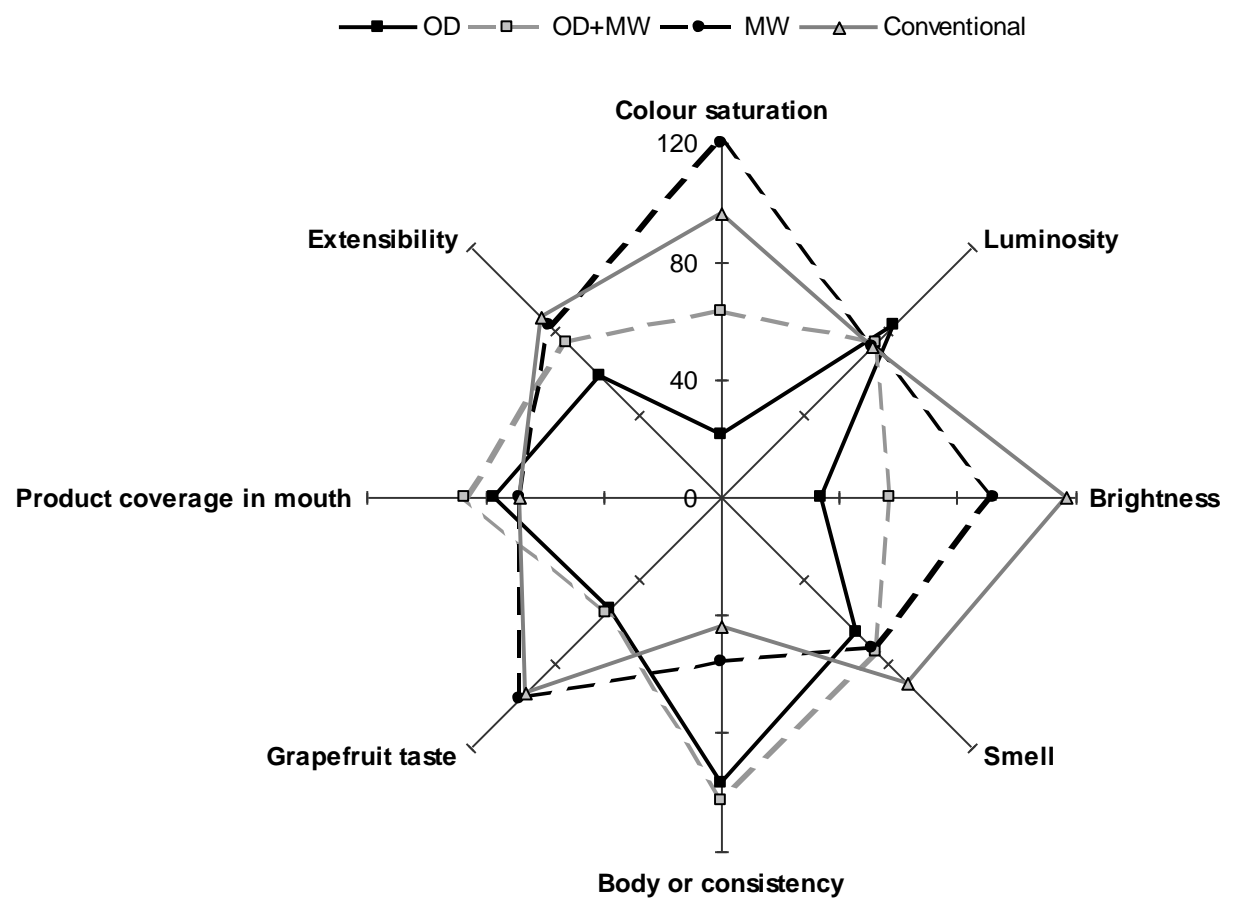

Figure 1. 


\section{Figure 2}

Click here to download Figure: Figure 2.doc

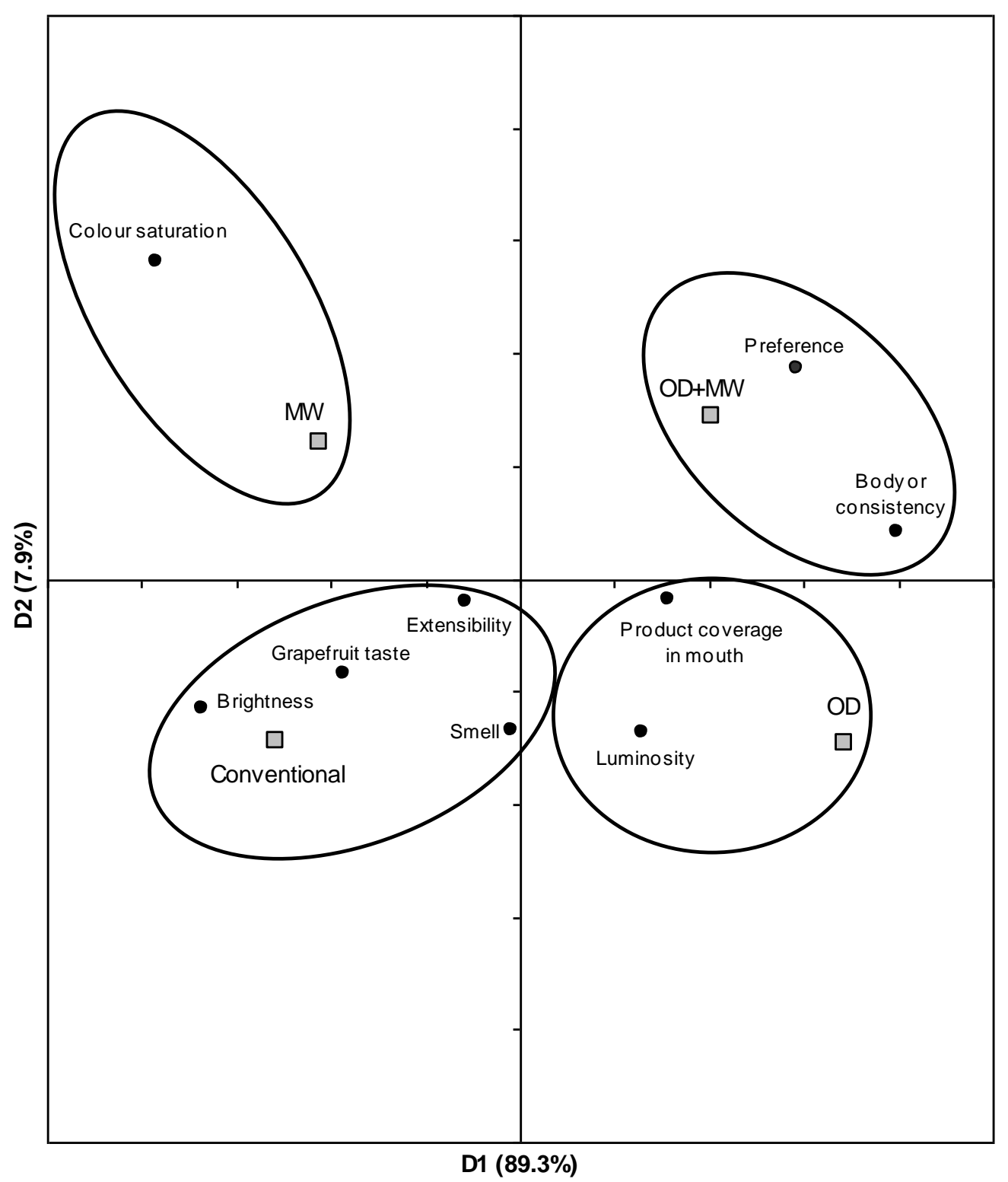

Figure 2. 
Figure 3

Click here to download Figure: Figure 3.doc
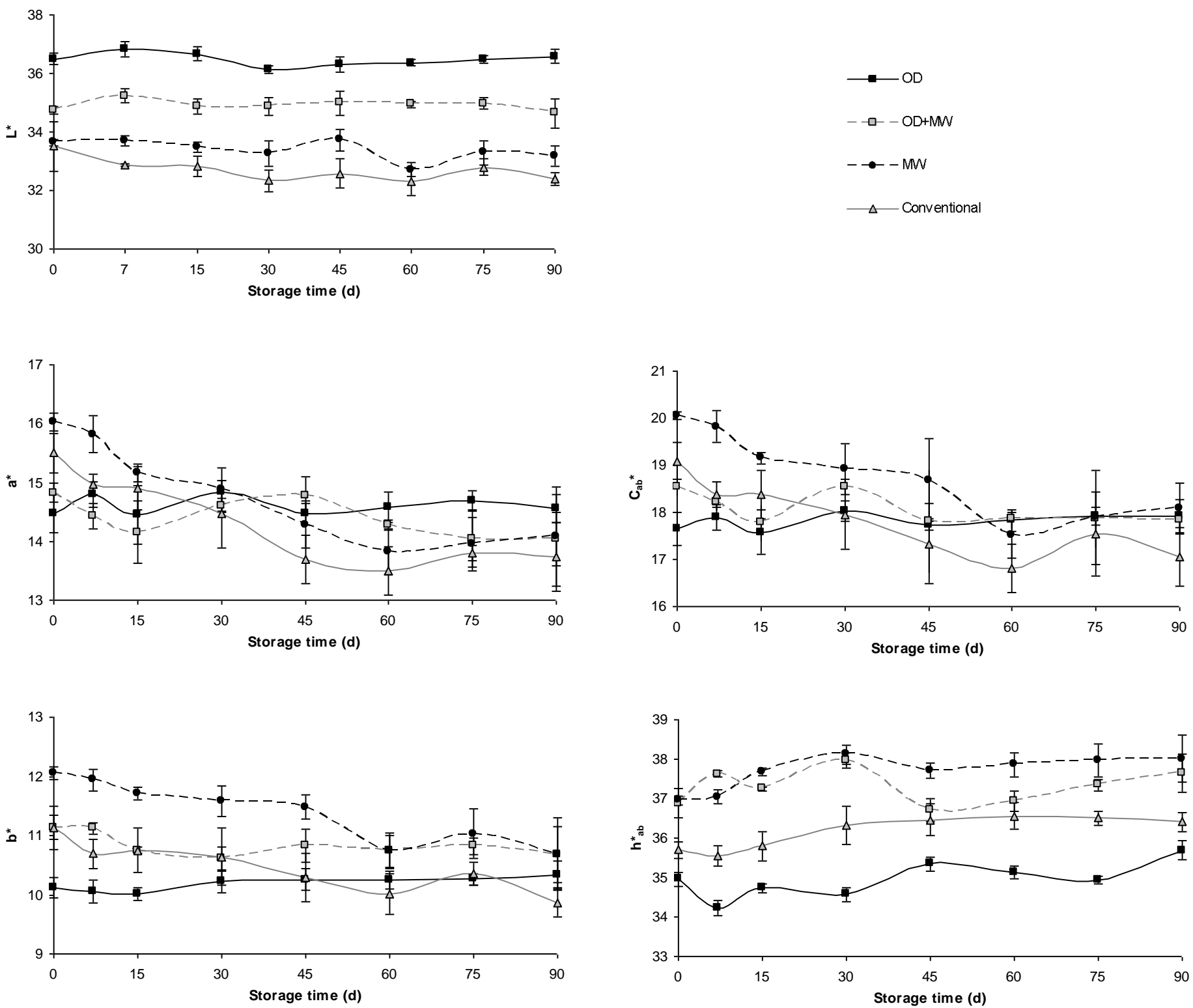

Figure 3. 


\section{Figure 4}

Click here to download Figure: Figure 4.doc

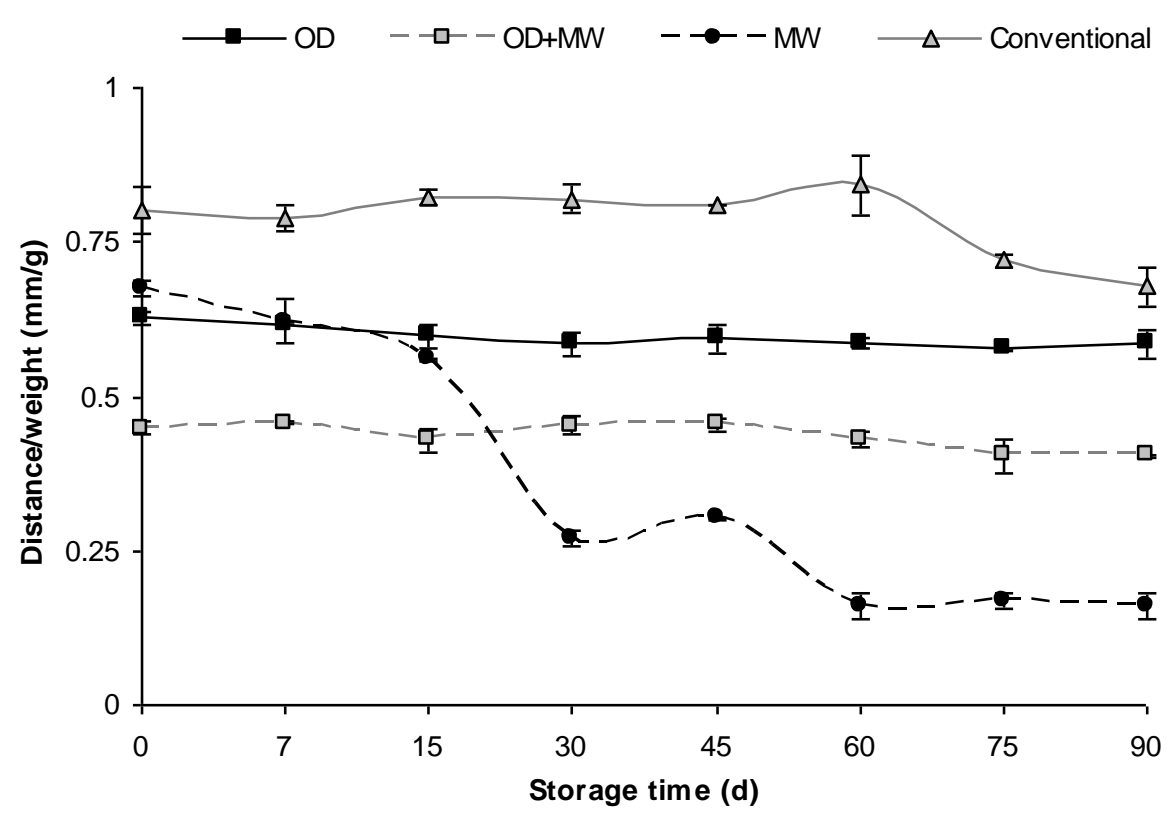

Figure 4. 
Click here to download Table: Table 1.doc

Table 1.

\begin{tabular}{lcccc}
\hline \multicolumn{1}{c}{ Samples } & 'Brix $^{\text {B }}$ & $\mathbf{a}_{\mathbf{w}}$ & $\mathbf{x}_{\mathbf{w}}\left(\mathbf{g}_{\mathbf{w}} / \mathbf{g}_{\text {product }}\right)$ & $\mathbf{p H}$ \\
\hline Fresh-fruit & $12.0(0.2)^{\mathrm{a}}$ & $0.989(0.003)^{\mathrm{a}}$ & $0.882(0.002)^{\mathrm{a}}$ & $3.27(0.02)^{\mathrm{b}}$ \\
Conventional $^{\mathrm{a}}$ & $48.5(0.2)^{\mathrm{d}}$ & $0.922(0.003)^{\mathrm{e}}$ & $0.526(0.002)^{\mathrm{e}}$ & $3.25(0.02)^{\mathrm{a}}$ \\
OD & $46.1(0.2)^{\mathrm{b}}$ & $0.945(0.003)^{\mathrm{b}}$ & $0.541(0.002)^{\mathrm{b}}$ & $3.39(0.02)^{\mathrm{c}}$ \\
OD+MW & $46.0(0.2)^{\mathrm{b}}$ & $0.942(0.003)^{\mathrm{c}}$ & $0.537(0.002)^{\mathrm{c}}$ & $3.40(0.02)^{\mathrm{c}}$ \\
MW & $47.7(0.2)^{\mathrm{c}}$ & $0.924(0.003)^{\mathrm{d}}$ & $0.529(0.002)^{\mathrm{d}}$ & $3.27(0.02)^{\mathrm{b}}$ \\
\hline
\end{tabular}

The same letter in superscript within columns indicates homogeneous groups established by the ANOVA $(p<0.05)$. 
Table 2.

\begin{tabular}{lccccc}
\hline & Fresh-fruit & Conventional & OD & OD+MW & MW \\
\hline $\mathbf{L}^{*}$ & $49.6(0.3)^{\mathrm{a}}$ & $33.5(0.8)^{\mathrm{d}}$ & $36.5(0.2)^{\mathrm{b}}$ & $34.7(0.2)^{\mathrm{c}}$ & $33.6(0.2)^{\mathrm{d}}$ \\
$\mathbf{a}^{*}$ & $20,6(0,2)^{\mathrm{a}}$ & $15,5(0,3)^{\mathrm{c}}$ & $14,5(0,3)^{\mathrm{e}}$ & $14,8(0,2)^{\mathrm{d}}$ & $16,02(0,16)^{\mathrm{b}}$ \\
$\mathbf{b}^{*}$ & $17,76(0,02)^{\mathrm{a}}$ & $11,1(0,2)^{\mathrm{c}}$ & $10,1(0,2)^{\mathrm{d}}$ & $11,1(0,4)^{\mathrm{c}}$ & $12,06(0,12)^{\mathrm{b}}$ \\
$\mathbf{C}^{*}{ }_{\mathrm{ab}}$ & $27.2(0.2)^{\mathrm{a}}$ & $19.1(0.4)^{\mathrm{c}}$ & $17.7(0.4)^{\mathrm{e}}$ & $18.5(0.2)^{\mathrm{d}}$ & $20.1(0.2)^{\mathrm{b}}$ \\
$\mathbf{h}^{*}{ }_{\mathrm{ab}}$ & $40.8(0.3)^{\mathrm{a}}$ & $35.7(0.3)^{\mathrm{c}}$ & $35.0(0.4)^{\mathrm{c}}$ & $37(2)^{\mathrm{b}}$ & $37.0(0.5)^{\mathrm{b}}$ \\
$\Delta \mathbf{E}_{\mathbf{1}}$ & - & $18.2(0.7)^{\mathrm{c}}$ & $16.4(0.2)^{\mathrm{a}}$ & $17.3(0.2)^{\mathrm{b}}$ & $17.6(0.3)^{\mathrm{bc}}$ \\
$\Delta \mathbf{E}_{\mathbf{2}}$ & - & - & $3(2)^{\mathrm{b}}$ & $1.5(0.8)^{\mathrm{a}}$ & $1.2(0.5)^{\mathrm{a}}$ \\
Distance/weight (mm/g) & - & $0.80(0.04)^{\mathrm{c}}$ & $0.63(0.02)^{\mathrm{b}}$ & $0.45(0.02)^{\mathrm{a}}$ & $0.68(0.02)^{\mathrm{b}}$ \\
\hline
\end{tabular}

The same letter in superscript within files indicates homogeneous groups established by the ANOVA ( $<<0.05)$. Colour differences of jam product as compared to fresh fruit $\left(\Delta \mathrm{E}_{1}\right)$ or conventional jam $\left(\Delta \mathrm{E}_{2}\right)$. 
Table 3

Click here to download Table: Table 3.doc

Table 3.

\begin{tabular}{lllllll}
\hline & $\begin{array}{l}\text { Colour } \\
\text { saturation }\end{array}$ & Brightness & $\begin{array}{l}\text { Body or } \\
\text { consistency }\end{array}$ & $\begin{array}{l}\text { Grapefruit } \\
\text { taste }\end{array}$ & Extensibility & Preference \\
\hline OD - OD+MW & $42^{*}$ & 23 & 6 & 2 & 16 & $28^{*}$ \\
OD - MW & $99^{*}$ & $58^{*}$ & $41^{*}$ & $42^{*}$ & 24 & 18 \\
OD - Conventional & $75^{*}$ & $83^{*}$ & $53^{*}$ & $40^{*}$ & $28^{*}$ & $32^{*}$ \\
OD+MW - MW & $57^{*}$ & $35^{*}$ & $47^{\star}$ & $40^{*}$ & 8 & $46^{\star}$ \\
OD+MW - Conventional & $33^{*}$ & $60^{*}$ & $59^{*}$ & $38^{*}$ & 12 & $60^{*}$ \\
MW - Conventional & 24 & 25 & 12 & 2 & 4 & 14 \\
\hline
\end{tabular}

*significant differences at the 0.05 level according Tukey HSD 
Click here to download Table: Table 4.doc

Table 4.

\begin{tabular}{lccc}
\hline \multicolumn{1}{c}{ Attribute/Jam } & D1 & D2 & Total \\
\hline Colour saturation & 0.860 & 0.135 & 0.995 \\
Luminosity & 0.637 & 0.210 & 0.847 \\
Brightness & 0.927 & 0.033 & 0.959 \\
Smell & 0.014 & 0.773 & 0.787 \\
Body or consistency & 0.995 & 0.003 & 0.999 \\
Grapefruit taste & 0.837 & 0.050 & 0.887 \\
Product coverage in mouth & 0.994 & 0.004 & 0.998 \\
Extensibility & 0.916 & 0.031 & 0.947 \\
Preference & 0.874 & 0.104 & 0.978 \\
OD & 0.936 & 0.05 & 0.987 \\
OD+MW & 0.829 & 0.123 & 0.952 \\
MW & 0.867 & 0.082 & 0.948 \\
Conventional & 0.897 & 0.084 & 0.981 \\
\hline
\end{tabular}


Click here to download Table: Table 5.doc

Table 5.

\begin{tabular}{|c|c|c|c|c|c|c|}
\hline & $L^{*}$ & $a^{*}$ & $\mathbf{b}^{*}$ & $\mathbf{C}^{\star}{ }_{a b}$ & $\mathbf{h}^{*}{ }_{a b}$ & Distance/weight $(\mathrm{mm} / \mathrm{g})$ \\
\hline Colour saturation & $-0.9745^{*}$ & 0.837 & 0.7311 & 0.8055 & 0.4184 & \\
\hline Luminosity & $0.9764^{\star}$ & -0.8179 & -0.8741 & -0.8618 & -0.7334 & \\
\hline Brightness & -0.9144 & $0.9984^{*}$ & 0.9227 & $0.985^{\star}$ & 0.5791 & \\
\hline $\begin{array}{l}\text { Body or consistency } \\
\text { Product coverage in mouth }\end{array}$ & & & & & & $\begin{array}{l}-0.9057 \\
-0.9552^{*}\end{array}$ \\
\hline Extensibility & & & & & & 0.4886 \\
\hline
\end{tabular}

*significant differences at the 0.05 level 